\title{
Intercambio mundial y regional de especias en términos de valor, 1992-2011
}

\author{
Global and regional exchange of spices \\ in terms of value, 1992-2011
}

OSVALDO PEDRO ARIZIO'

ANA OFELIA CURIONI',2

\begin{tabular}{l} 
Mostaza, pimentón, coriandro, \\
hinojo, nuez moscada, canela en \\
rama, pimienta en granos, tomillo, \\
ají molido, clavo de olor y otras \\
especias. \\
Foto: O.P. Arizio \\
\hline
\end{tabular}

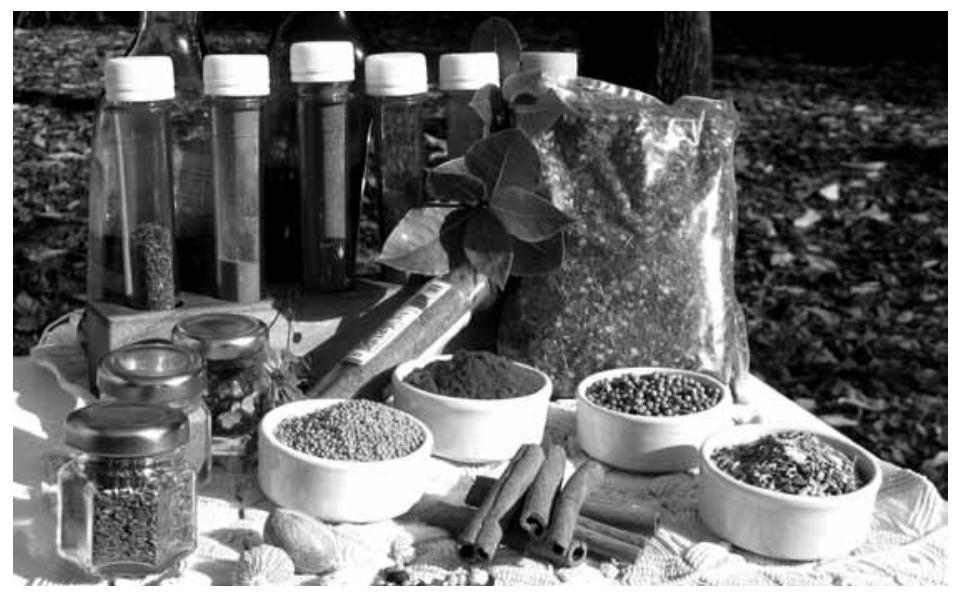

\section{RESUMEN}

El comercio internacional de especias ha venido experimentado un constante crecimiento a partir de los años 1970, con ritmos que duplican o triplican, el crecimiento de la población mundial. Los objetivos de este trabajo son comprobar si durante las dos últimas décadas se mantiene la tendencia de altos ritmos de crecimiento del intercambio mundial de especias, detectar los países importadores y exportadores a nivel mundial y Sudamericano y los productos del intercambio mundial de especias. Para ello se tomó como base a los productos incluidos en el grupo 075 de la Clasificación Única para el Comercio Internacional (2008), equivalente con las posiciones arancelarias del Sistema Armonizado 0904.11 a 0910.99, a los que se ha adicionado las semillas de mostaza que es incluida dentro de las especias por algunos países. Los datos obtenidos de Naciones Unidas (1992-2011) fueron organizados y sistematizados, obteniéndose los promedios quinquenales, las participaciones porcentuales de países y productos y las tasas de crecimiento anual promedio por el método de regresión lineal. El intercambio mundial de especias ha continuado creciendo a importantes tasas y los países sudamericanos participan de las mismas tendencias que a nivel mundial. Se observa una importante concentración en pocos países tanto de las importaciones como de las exportaciones de estos productos. Estados Unidos, Alemania y Japón, a su vez asiento de una fuerte industria de alimentos, son los principales importadores, mientras que India, China y Vietnam se destacan como los principales exportadores. La región Sudamericana presenta superávit debido a las exportaciones de Brasil y Perú, los restantes países de la región son principalmente importadores de especias.

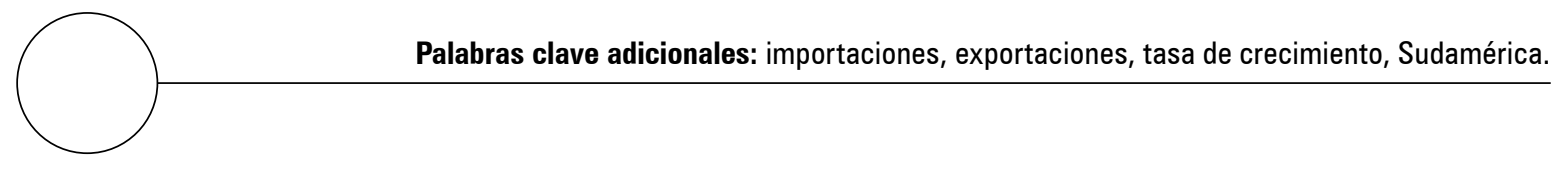

\footnotetext{
Departamento de Tecnología, Universidad Nacional de Luján, Buenos Aires (Argentina)

2 Autor para correspondencia. curioniao@gmail.com
} 


\section{ABSTRACT}

The international spice trade has experienced constant growth since 1970, with rates that are double or triple the global population growth rate. The objectives of this study were to verify if during the last two decades the high rates of global spice exchange were maintained and to detect the importing and exporting countries at the global and South American levels and the products of the global spice exchange. To do so, products from group 075 of the Unique Classification for the International Trade were taken as a starting point, equivalent to the tariff positions of the Harmornized System 0904.11 to 0910.99, to which mustard seeds were included within the spices of some countries. The data collected from the United Nations (19922011) were organized and systematized, obtaining the quinquennial averages, the percentage participation of countries and products, and the rates of annual growth average by the linear regression method. The global spice exchange has continued growing to important rates and South American countries participate with the same tendencies as at the global level. It was observed that an important part of the imports and exports of these products is concentrated in a few countries. The United States, Germany and Japan are the main importers, whereas India, China and Vietnam stand out as the main exporters. The South American region presents surplus due to the exports of Brazil and Peru, the remaining countries of the region are mainly spice importers.

Additional key words: imports, exports, growth rate, South America.

Fecha de recepción: 06-02-2014

Aprobado para publicación: 03-06-2014
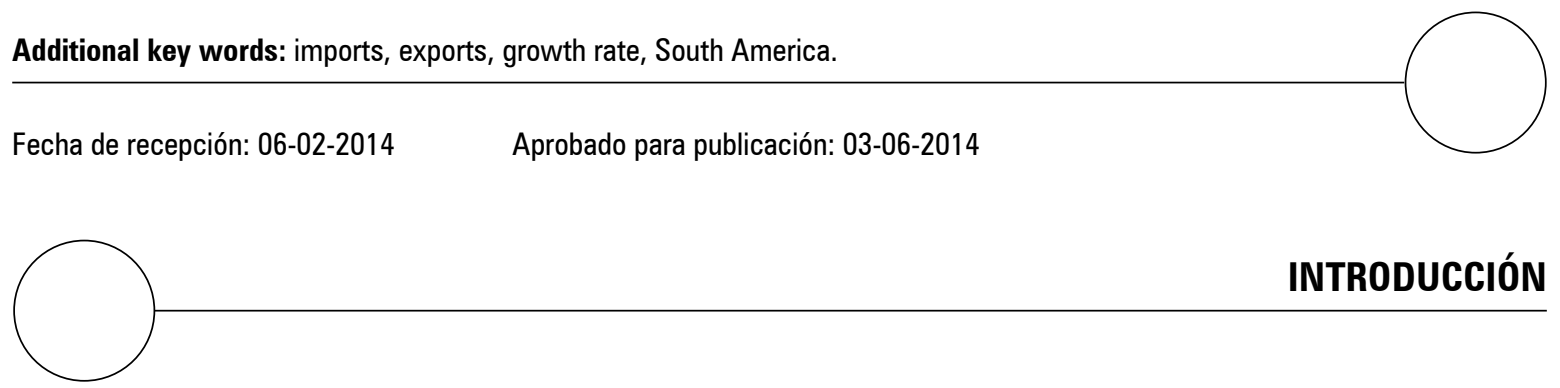

Las especias han sido utilizadas durante siglos por el sabor que imparten a los alimentos así como la capacidad de algunas especias para preservar los alimentos (American Spice Trade Association, 2011). Se define a las especias como aquellas sustancias vegetales de intenso sabor y aroma, utilizadas generalmente como condimentos o empleadas con otros propósitos en vista de sus cualidades aromáticas y de preservación (antioxidantes naturales); otras definiciones, producto de origen vegetal seco, utilizado principalmente para condimento, ya sea la semilla, corteza, hojas y flores, los cuales pueden ser comercializados, molido o en forma de aceites esenciales y oleorresinas o semilla seca, fruta, raíz, corteza u hojas utilizadas en cantidades nutricionalmente insignificantes como un aditivo, con el propósito de condimentación y a veces como conservante (Yimer, 2010). La European Spices Asociation (ESA) menciona que las hierbas culinarias y especias son partes comestibles de plantas que tradicionalmente se agregan a los productos alimenticios por su aroma natural, propiedades aromáticas y visuales. Por su parte, la International Organization of Spice Trade Association (2013) especifica que las especias son semillas secas, frutas, bayas, hojas, raíces o cortezas de plantas cultivadas como hierbas, arbustos, trepadoras y árboles, utilizados para realzar el sabor de los alimentos. Es decir que en todos los casos se recalca su origen vegetal, involucra distintas partes de la planta cumpliendo funciones saborizantes y condimentarias y de conservación de los alimentos.

Gran parte del consumo de especias del mundo tiene su origen en las exportaciones de alguna de las regiones más pobres del mundo. Una parte importante del volumen producido en los 
principales países productores y exportadores es destinado a su propio consumo interno (India es considerado el principal productor mundial), por otra parte, otro volumen considerable de producción es destinado a la obtención de oleorresinas y aceites esenciales. Estos hechos hacen que la producción y el consumo mundial presenten un volumen mucho más elevado que el que se comercializa mundialmente (Centro de Comercio Internacional, 1982).

El consumo total de especias y hierbas condimentarias, tanto en los países centrales como periféricos, depende de la magnitud de la población, el nivel de ingreso, el estado de su economía y de las costumbres culinarias y sociales. Por otra parte, el consumo por habitante tanto del total de especies como de los distintos tipos, varía ampliamente de una zona a otra, incluso dentro de cada uno de los países de acuerdo con su cultura culinaria (Arizio y Curioni, 2003).

En los países periféricos o en vías de desarrollo el consumo de especies y hierbas condimentarias continúa siendo predominantemente doméstico, en tanto que en los países industrializados tiene como destino especial la industria alimenticia (carne, pescados, verduras, legumbres, productos de panadería y otros alimentos preparados y listos para su consumo). En casi todos los casos, la industria cárnica es el primer usuario de una amplia gama de especias, entre las que sobresale la pimienta, seguida de la industria láctea y de bebidas.

La venta minorista para el consumo doméstico ha tenido una tendencia a la baja, al incorporarse a la población activa un número cada vez mayor de mujeres, con la consiguiente caída en la preparación de comidas en el hogar. El crecimiento de la industria de elaboración de alimentos se ha realizado a expensas del sector de la venta al detalle, ya que las familias comen en mayor proporción alimentos precocinados o fuera de su hogar en establecimientos de comidas rápidas. (Centro de Comercio Internacional, 1982).
El comercio internacional de especias ha venido experimentado un constante crecimiento a partir de los años 1970, con ritmos que duplican o triplican, según los casos, el crecimiento de la población mundial y de determinados mercados en particular (Husain, 1992 y 1996). Shinoj and Mathur (2006) afirman que en la India, el cambio en las preferencias de los consumidores nacionales de alimentos, la creciente urbanización y el aumento de los ingresos, alteran los factores demográficos y sociales y los cambios en la productividad de las especias dando lugar a cambios en el patrón de su consumo y la demanda.

Esta expansión de la demanda se da, según Arizio y Curioni (2003) a través de: (a) Los cambios en los hábitos de consumo donde las comidas preelaboradas o precocinadas muestran una tendencia clara a reemplazar las comidas de elaboración casera, lo que ha dado impulso y sustento a la aparición de nuevas tecnologías de envasado, cocción y conservación de alimentos. Este hecho ha determinado que la demanda de la industria alimenticia de condimentos sea hoy superior a la demanda de las economías domésticas. Estas comidas preelaboradas necesitan de conservantes naturales, propiedad que por sus condiciones antioxidantes, además de brindar aroma y sabor, presentan las especias. (b) Las tendencias hacia una vida más sana y natural, que está imponiendo el uso de saborizantes, suplementos y conservantes de origen natural, como una clara tendencia de reemplazo a los productos de síntesis y a un menor consumo de sal, lo que obliga a un mayor empleo de condimentos para la sustitución de su sabor. (c) El auge de las denominadas comidas étnicas, producto de las grandes migraciones ocurridas hacia los países industrializados de etnias cuya cultura culinaria utiliza una gran variedad y cantidad de condimentos; tales como la de mejicanos hacia Estados Unidos, de países Árabes y africanos hacia Europa o desde el sudeste asiático hacia ambos destinos. Estas migraciones llevaron sus comidas y sabores que paula- 
tinamente fueron incorporados por las civilizaciones occidentales tradicionales. (d) Una clara tendencia al reemplazo en la industria alimenticia de condimentos en su estado natural por los aceites esenciales y oleorresinas, dadas las ventajas que estos ofrecen respecto a los sólidos (menor volumen, mejor conservación, menores fletes y espacio de almacenaje, mejor dispersión en la mezcla alimenticia). Las industrias de oleorresinas son complejos tecnológicos de gran escala de procesamiento, lo que implica la importación de especias en gran cantidad para su abastecimiento, más allá de la producción propia de un país, que en la mayoría de los casos presenta estacionalidad.

Todos estos elementos se conjugan para explicar por qué hoy la tendencia de crecimiento en la demanda de especias tiene su centro en la industria de alimentos, en especial la industria cárnica, láctea y de bebidas. Este hecho se verifica en la actualidad incluso para los aceites esenciales, donde otrora su demanda se encontraba altamente traccionada por la industria perfumista y de desodorización y limpieza ambiental.

Conocer cuál ha sido el comportamiento del mercado mundial de especias permite definir estrategias de políticas públicas así como de los sectores productivos vinculados con estos productos, tanto del sector primario como el del sector de transformación industrial.

Los objetivos que se buscan alcanzar con este trabajo son: (1) comprobar si durante las dos últimas décadas se mantiene la tendencia de altos ritmos de crecimiento del intercambio mundial de especias, como los observados durante los años 1970 y 1980, y si el mercado regional de América del Sur se corresponde con dicha tendencia mundial; (2) identificar los principales países importadores y exportadores a nivel mundial y sudamericano y (3) determinar los principales productos del intercambio mundial de especias.

\section{MATERIALES Y MÉTODOS}

Para el presente estudio se define como especia a un conjunto de materiales vegetales, en su estado natural o con un mínimo grado de transformación, en general granos y hojas secas, de intenso sabor y aroma, utilizadas principalmente como condimentos por sus cualidades aromáticas y de preservación. Estas se encuentran reunidas en el Grupo 075 de la Clasificación Única para el Comercio Internacional (2008), equivalente con las posiciones arancelarias del Sistema Armonizado 0904.11 a 0910.99, a los que se ha adicionado las semillas de mostaza que es incluida dentro de las especias por algunos países.

De esta forma los productos a considerar aquí como especias (con su respectiva posición de sistema armonizado) son los siguientes: pimienta (0904.11/12), frutos de Capsicum sp. y Pimenta sp. (0904.20), vainilla (0905.00), canela (0906.00), clavo (0907.00), nuez moscada, macis y cardamomo (0908.10/20/30), anís y badiana (0909.11/12), coriandro (0909.20), comino (0909.30), alcaravea (0909.40), hinojo y bayas de enebro (0909.50), jengibre (0910.10), azafrán (0910.20), cúrcuma (0910.30), tomillo y laurel (0910.40), curry (0910.50), las demás especias (0910.91), mezclas de especias (0910.99) y semillas de mostaza (1207.50).

Para las posiciones arriba indicadas se obtuvieron datos de importaciones y exportaciones en su máximo grado de apertura por país de origen o destino de la base de datos de Naciones Unidas (United Nations Commodity Trade Statistics Database) de los últimos 20 años disponibles (1992 a 2011). Dichos datos fueron organizados y sistematizados en cuadros obteniéndose los promedios quinquenales, las participaciones porcentuales tanto de países como de productos y las tasas de crecimiento anual promedio por el método de regresión lineal utilizando el tiempo como variable independiente. De esta manera fueron determinados los 
principales países importadores y exportadores mundiales y los principales productos del intercambio mundial de especias.

Por último, se procedió de igual manera para los países que conforman el conglomerado de Sudamérica. En base a los datos obtenidos y de su comparación con periodos previos se extraen las conclusiones finales.

\section{RESULTADOS Y DISCUSIÓN}

\section{Evolución de las importaciones mundiales}

Las importaciones mundiales de especias en términos de valor, han continuado expandiéndose hasta alcanzar en el año 2011 los casi 7.300 millones de dólares (figura 1). Esta expansión ha mantenido ritmos semejantes a los observados durante las décadas del setenta y ochenta (Arizio y Curioni, 2003), tal como lo demuestran las tasas de crecimiento anua- les del 8,1\% durante los últimos 20 años y del $10,8 \%$ durante la última década considerada. Solo se detectan leves disminuciones en 2001 y 2002 (US $\$ 2.475$ millones promedio), en 2005 y 2006 (US $\$ 3.181$ millones promedio) y en 2009 (US\$4.570 millones). Sorprende el incremento registrado en los últimos cinco años, donde el intercambio en términos de valor sufre un incremento de casi el $80 \%$, pasando de un valor anual promedio para el quinquenio 2002-2006 de US\$2.992 millones a US\$5.351 en el quinquenio 2007-2011, este incremento fue traccionado principalmente por el alza de los precios registrados en gran parte de los commodities agrícolas.

En términos de valor las importaciones mundiales de especias 1992-2011, han continuado expandiéndose a ritmos similares a los de las décadas precedentes. El último quinquenio analizado muestra un incremento cercano al $80 \%$, producto de la tracción ejercida por el alza de los precios de los commodities.

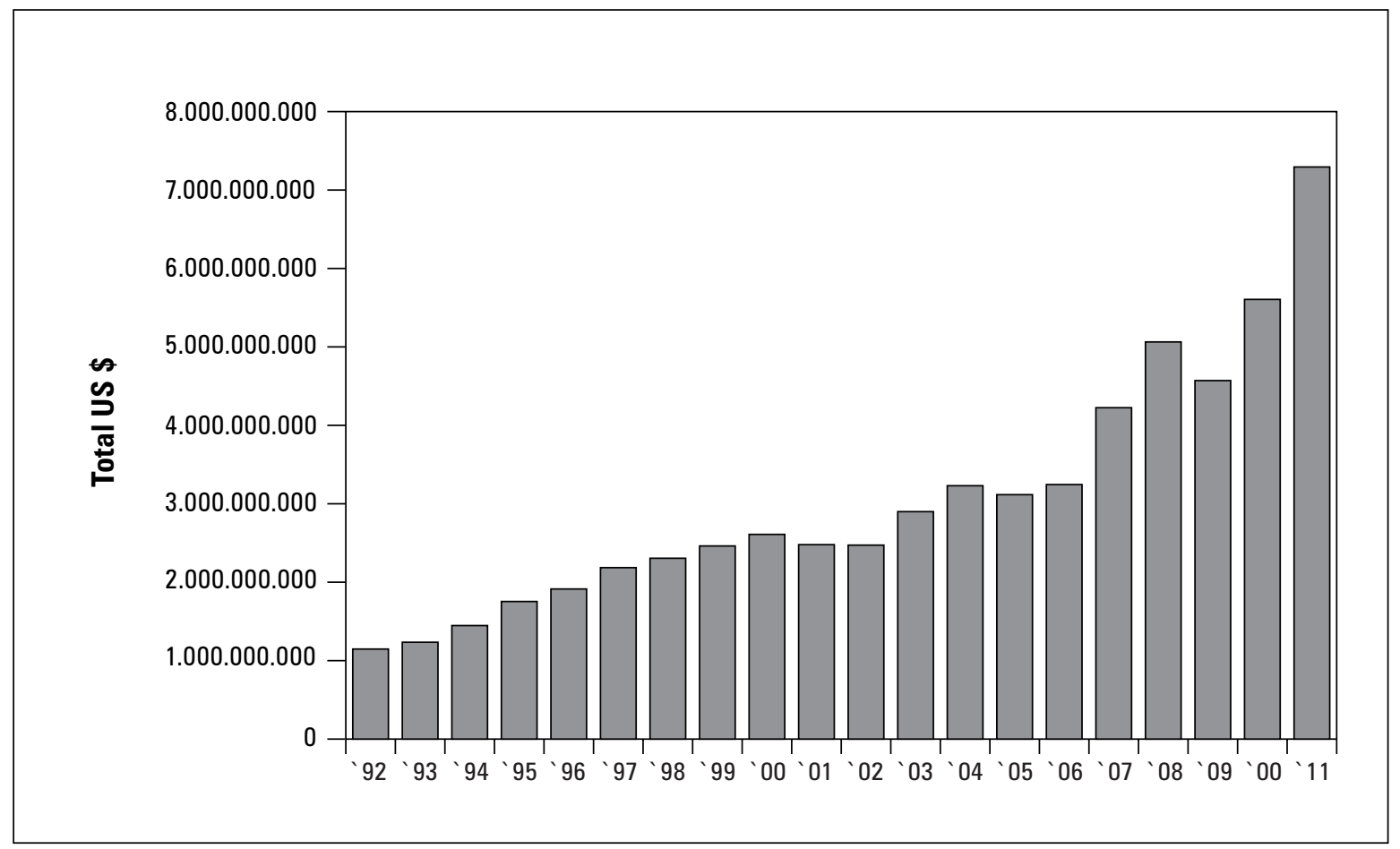

Figura 1. Evolución de las importaciones mundiales de especias 1992-2011 (elaborado en base a datos de United Nations Commodity Trade Statistics Database). 


\section{Principales países importadores y exportadores mundiales}

Los principales países importadores son Estados Unidos, Alemania y Japón, que en conjunto representan el $26,8 \%$ de las importaciones mundiales de especias en términos de valor anual promedio para el quinquenio 2007-2011, países que poseen las mayores industrias alimenticias del mundo (tabla 1).

Existe una alta concentración de las importaciones de especias ya que los primeros $10 \mathrm{im}$ portadores mundiales concentran el $52,7 \%$ de las importaciones de estos productos. Dentro de los principales 10 importadores se observan tres países, que también se destacan por sus exportaciones de especias, Alemania y Países Bajos dado que actúan como puerta de ingreso a toda Europa a través de los puertos de Hamburgo y Rotterdam y por lo tanto se destacan por las reexportaciones de especias. El otro país es Singapur, punto neurálgico del sudeste asiático que actúa como centro comercial de dicha región.
En efecto, una gran parte del comercio de exportación de la Unión Europea (UE) consiste en especias y hierbas que han sido importadas a granel o en forma cruda y que, después de su molienda, procesamiento o reenvasado, son reexportados a otros mercados de ultramar y de la propio UE. Las únicas especias que se originan en grandes cantidades dentro de la UE son semillas de alcaravea, pimentón y azafrán. Países Bajos y Alemania muestran una larga tradición al respecto (CBI Market, 2010).

Llama la atención la ubicación de España como octavo importador mundial de especias, también destacado exportador de estos productos. La razón de dicha ubicación destacada es que España en el último tiempo se ha convertido en un fuerte importador de pimientos para abastecer su planta de oleorresinas de pimentón. Además está aprovechando su histórica posición comercializadora en azafrán y anís, productos que prácticamente ha dejado de producir y que continúa comercializando a nivel mundial a partir de importaciones originadas en Irán y Turquía.

Tabla 1. Principales países importadores de especias. Valor promedio anual del quinquenio 2007-2011 y tasa de crecimiento promedio del decenio 2002-2011 (elaborado en base a datos de United Nations Commodity Trade Statistics Database).

\begin{tabular}{|l|c|c|c|c|}
\multicolumn{1}{c|}{ Países } & $\begin{array}{c}\text { Promedio 2007-2011 } \\
\text { (millones de US\$) }\end{array}$ & $\begin{array}{c}\text { Porcentaje } \\
(\%)\end{array}$ & $\begin{array}{c}\text { Acumulado } \\
(\%)\end{array}$ & $\begin{array}{c}\text { Tasa crecimiento anual } \\
2002-2011\end{array}$ \\
\hline Estados Unidos & 809,9 & 15,1 & 15,1 & 5,9 \\
\hline Alemania & 353,3 & 6,6 & 21,7 & 6,2 \\
\hline Japón & 269,2 & 5,0 & 26,8 & 11,1 \\
\hline Países Bajos & 218,6 & 4,1 & 30,8 & 12,1 \\
\hline Reino Unido & 206,4 & 3,9 & 34,7 & 12,8 \\
\hline Emiratos Arabes & 201,7 & 3,8 & 38,5 & 11,8 \\
\hline India & 196,6 & 3,7 & 42,1 & 12,2 \\
\hline España & 190,5 & 3,6 & 45,7 & 5,3 \\
\hline Singapur & 189,1 & 3,5 & 49,2 & 12,3 \\
\hline Arabia Saudita & 185,5 & 3,5 & 52,7 & 13,8 \\
\hline Resto & $2.530,9$ & 47,3 & 100,0 & 10,8 \\
\hline Total mundial & $5.351,6$ & 100,0 & & \\
\hline
\end{tabular}


La India ocupa el séptimo lugar como importador de especias, siendo considerado el primer productor y consumidor mundial y uno de los más importantes exportadores. Las importaciones indias de especias son de pimienta, semillas de amapola, clavo de olor, cardamomo, jengibre fresco y cassia. El $60 \%$ de las importaciones de pimienta tienen como destino su industria de extracción de oleorresina (Parthasarathy et al., 2011).

En los últimos años, a los mercados del Oriente Medio, en particular Arabia Saudita (3,3\%) y Emiratos Árabes Unidos (2,8\%), les ha correspondido una parte considerable y creciente del comercio de especias, debido en gran medida a sus importaciones de cardamomo y pimienta.

De los 10 primeros importadores mundiales de especias, los países que han experimentado los mayores ritmos de crecimiento anual de sus importaciones durante la última década fueron Emiratos Árabes Unidos (12,8\%), Arabia Saudita $(12,3 \%)$ y España (12,2\%); mientras que Singapur (5,3\%), Estados Unidos (5,9\%) y Japón $(6,2 \%)$ presentan tasas anuales muy modestas comparadas con las correspondientes a las importaciones totales de especias $(10,8 \%)$ (tabla 1$)$.

También las exportaciones de especias muestran un alto nivel de concentración ya que los primeros 10 países exportadores concentran el 64\% del total (tabla 2). India, China y Vietnam son los grandes exportadores de especias representando en conjunto algo más del 35\% del total mundial.

La India es conocida como la "tierra de las especias". De 109 especies listadas por la Organización Internacional de Normalización (ISO), la India produce 63 debido a sus variadas condiciones agroclimáticas (Sahu y Mishra, 2013). Según la FAO, la superficie cosechada de especias en la India alcanzó las 765.103 ha con una producción de $1.525 .106 \mathrm{t}$, representando respectivamente el $76 \%$ y $72 \%$ del total mundial.

La importancia del consumo interno de especias de la India sobresale cuando se observa que sus exportaciones de especias son apenas el 12\% de su producción total (Parthasarathy et al., 2011) y con ello a su vez es el primer exportador mundial.

Tabla 2. Principales países exportadores de especias. Valor promedio anual del quinquenio 2007-2011 y tasa de crecimiento promedio del decenio 2002-2011 (elaborado en base a datos de United Nations Commodity Trade Statistics Database).

\begin{tabular}{|l|c|c|c|c|}
\multicolumn{1}{c|}{ Países } & $\begin{array}{c}\text { Promedio 2007-2011 } \\
\text { (millones de US\$) }\end{array}$ & $\begin{array}{c}\text { Porcentaje } \\
(\%)\end{array}$ & $\begin{array}{c}\text { Acumulado } \\
(\%)\end{array}$ & $\begin{array}{c}\text { Tasa crecimiento anual } \\
2002-2011\end{array}$ \\
\hline India & 918,7 & 15,9 & 15,9 & 21,9 \\
\hline China & 652,3 & 11,3 & 27,1 & 14,6 \\
\hline Viet Nam & 365,6 & 8,0 & 35,1 & 11,1 \\
\hline Indonesia & 348,4 & 6,0 & 41,2 & 14,2 \\
\hline Países Bajos & 259,8 & 4,5 & 45,6 & 17,6 \\
\hline Guatemala & 243,8 & 4,2 & 49,8 & 16,0 \\
\hline Irán & 224,7 & 3,9 & 53,7 & 9,6 \\
\hline Alemania & 218,8 & 3,8 & 57,5 & 5,2 \\
\hline Singapur & 210,2 & 3,6 & 61,1 & 10,9 \\
\hline España & 188,4 & 3,2 & 64,4 & 6,2 \\
\hline Resto & 2064,8 & 35,6 & 100,0 & 11,8 \\
\hline Total mundial & 5795,6 & 100,0 & & \\
\hline
\end{tabular}


India se destaca por sus exportaciones de Capsicum sp., pimienta, comino, jengibre y nuez moscada. China, por sus exportaciones de jengibre, Capsicum sp., canela, badiana y pimienta. Vietnam es exportador de pimienta, canela y nuez moscada. Guatemala es el principal productor y exportador de cardamomo.

Irán es hoy el principal productor y exportador de azafrán, correspondiéndole entre el 90\% y 93\% de la producción mundial (Ghorbani, 2008). Aghdaie et al. (2012) indican que la superficie mundial de azafrán es de 55.897 ha correspondiendo a Irán unas 47.208 ha, seguido por España con apenas 4.184 ha e India con 2.440 ha, mostrando la importante brecha productiva entre Irán y los restantes países productores de azafrán.

De los principales 10 exportadores mundiales de especias, quienes más han expandido las mismas durante el último decenio fueron India (21,9\%), Vietnam (20,4\%) y Guatemala (17,6\%); mientras que Singapur $(5,2 \%)$ y Alemania $(9,6 \%)$ son los que muestran menores ritmos de crecimiento anual en dicho periodo (tabla 2).

Para el quinquenio 2007-2011, Estados Unidos, Alemania y Japón, representan el 26,8\% de las importaciones mundiales de especias en términos de valor anual promedio, estos países poseen las mayores industrias alimenticias. Los primeros $10 \mathrm{im}$ portadores mundiales concentran casi el 53\% de las importaciones de estos productos. En relación a las exportaciones de especias, los primeros 10 países concentran el $64 \%$ del total, de este, India, China y Vietnam ostentan 35\% del total mundial.

\section{Principales productos del intercambio mundial de especias}

Si se excluyen las posiciones bolsas "Las demás" y las "Mezclas de especias", la pimienta, los productos derivados del género Capsicum sp. (pimiento seco entero, triturado o molido) y el jengibre representan casi la mitad del intercambio mundial de especias en términos de valor (figura 2).

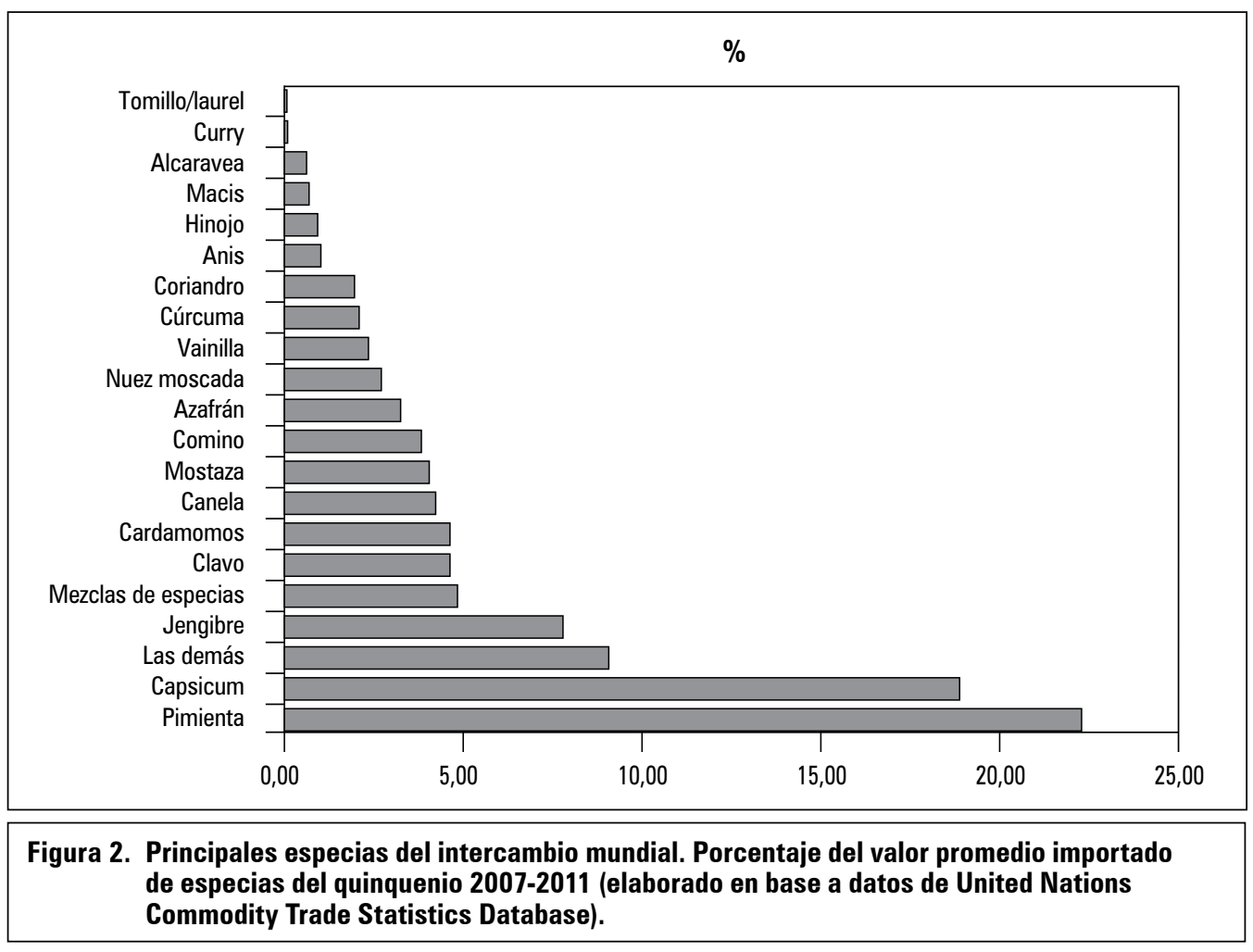


Al analizar los ritmos de crecimiento anual promedio durante el último decenio se observa que las mayores expansiones en las importaciones de especias corresponden a la cúrcuma (18,3\%) y al azafrán (17,1\%), mientras que solo tres productos presentan tasas negativas, el polvo curry $(-56,1 \%)$, el tomillo y laurel $(-45,6 \%)$ y la vainilla $(-14,6 \%)$ (figura 3).

El 50\% del intercambio mundial de especias corresponden a la pimienta, derivados de Capsicum sp. y jengibre. El mayor crecimiento se dio para la cúrcuma y el azafrán.

\section{El intercambio comercial de especias en América del Sur}

América del Sur como región muestra un saldo comercial superavitario en el intercambio de especias y no es ajena a las tendencias observadas en el comercio mundial de estos productos, tal como lo demuestra el crecimiento de sus importaciones y exportaciones (figura 4).
Sin embargo el saldo comercial positivo de la región es producto del generado básicamente por Brasil y Perú y la colaboración en menor medida de Chile y Surinam, ya que los restantes países de la región muestran saldos comerciales deficitarios en el intercambio de especias (tabla 3).

En efecto durante la última década las importaciones de especias de América del Sur han crecido a un ritmo del $11,5 \%$ anual alcanzando hacia 2011 los 136 millones de dólares (tabla 4). Los principales países importadores son Brasil, Argentina y Venezuela que en conjunto concentran casi el 59\% de las importaciones de especias de la región. A su vez Paraguay, Venezuela y Argentina son los que muestran las mayores expansiones de sus importaciones durante el decenio como demuestran sus tasas de crecimiento anual promedio en términos de valor del $27,6 \%, 20,4 \%$ y $18,9 \%$ respectivamente (tabla 4). La menor expansión corresponde a Bolivia con una tasa del 2,6\% anual.

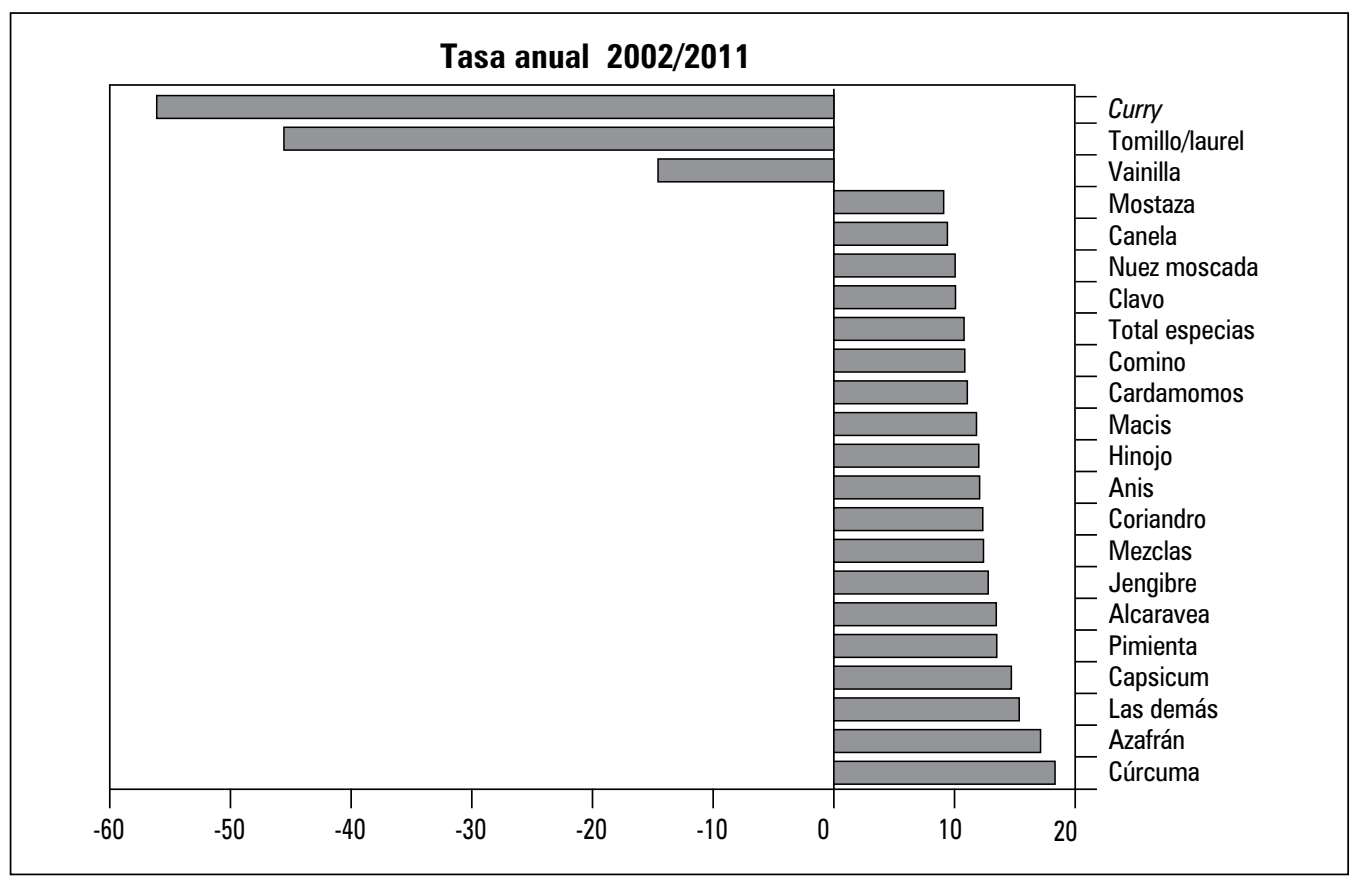

Figura 3. Ritmos de crecimiento anual por especia del último decenio. Tasas anuales promedio acumulativas en términos de valor de las importaciones mundiales 2002-2011 (elaborado en base a datos de United Nations Commodity Trade Statistics Database). 


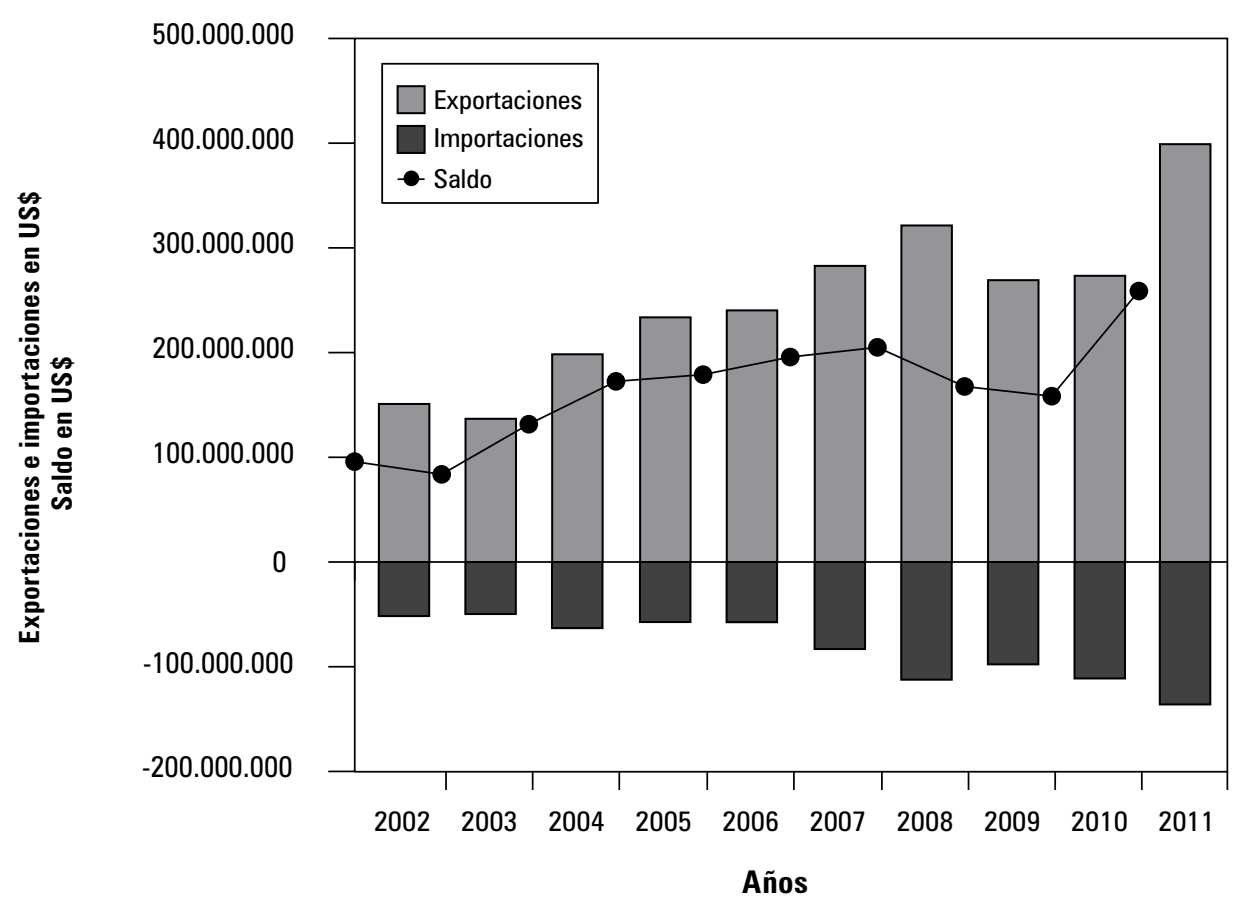

Figura 4. Evolución de las importaciones, exportaciones y saldo comercial de especias de América del Sur 2002-2011 (elaborado en base a datos de United Nations Commodity Trade Statistics Database).

Tabla 3. Importaciones, exportaciones y saldo comercial de especias de países de América del Sur. Valor promedio quinquenio 2007-2011 (elaborado en base a datos de United Nations Commodity Trade Statistics Database).

\begin{tabular}{|l|r|r|r|}
\multicolumn{1}{c|}{ País } & Importaciones (US\$) & Exportaciones (US\$) & Saldo comercial (US\$) \\
\hline Brasil & 162.594 .678 & 30.283 .680 & 132.310 .998 \\
\hline Peru & 117.318 .300 & 8.843 .256 & 108.475 .044 \\
\hline Chile & 13.455 .084 & 7.254 .117 & 6.200 .966 \\
\hline Surinam & 662.453 & 316.264 & 346.189 \\
\hline Bolivia & 907.299 & 1.091 .615 & -184.315 \\
\hline Guyana & 519.245 & 1.091 .927 & -572.682 \\
\hline Uruguay & 11.292 & 1.857 .593 & -1.846 .301 \\
\hline Paraguay & 11.167 & 1.967 .821 & -1.956 .655 \\
\hline Ecuador & 4.982 .810 & 9.949 .918 & -4.967 .108 \\
\hline Colombia & 6.554 .061 & 11.792 .278 & -5.243 .217 \\
\hline Venezuela & 13.697 & 13.495 .612 & -13.481 .915 \\
\hline Argentina & 2.116 .741 & 20.148 .682 & -18.031 .942 \\
\hline América del Sur & 309.146 .826 & 108.097 .764 & 201.049 .062 \\
\hline
\end{tabular}


Tabla 4. Importaciones de especias de América del Sur por país. Valor promedio quinquenio 2007-2011 y tasa de crecimiento promedio del decenio 2002-2011 (elaborado en base a datos de United Nations Commodity Trade Statistics Database).

\begin{tabular}{|l|r|r|r|r|}
\multicolumn{1}{|c|}{ Países } & $\begin{array}{c}\text { Promedio 2007-2011 } \\
\text { (US\$) }\end{array}$ & $\begin{array}{c}\text { Procentaje } \\
(\%)\end{array}$ & $\begin{array}{c}\text { Acumulado } \\
(\%)\end{array}$ & $\begin{array}{c}\text { Tasa crecimiento anual } \\
\text { (2002-2011) }\end{array}$ \\
\hline Brasil & 30.283 .680 & 28,0 & 28,0 & 6,8 \\
\hline Argentina & 20.148 .682 & 18,6 & 46,7 & 20,4 \\
\hline Venezuela & 13.495 .612 & 12,5 & 59,1 & 12,2 \\
\hline Colombia & 11.797 .278 & 10,9 & 70,1 & 5,9 \\
\hline Ecuador & 9.949 .918 & 9,2 & 79,3 & 13,6 \\
\hline Perú & 8.843 .256 & 8,2 & 87,4 & 27,6 \\
\hline Chile & 7.254 .117 & 6,7 & 94,1 & 12,8 \\
\hline Paraguay & 1.967 .821 & 1,8 & 96,0 & 15,1 \\
\hline Uruguay & 1.857 .593 & 1,7 & 97,7 & 2,6 \\
\hline Guyana & 1.091 .927 & 1,0 & 98,7 & 11,5 \\
\hline Bolivia & 1.091 .615 & 1,0 & 99,7 & 6,6 \\
\hline Surinam & 316.264 & 0,3 & 100,0 & \\
\hline América del Sur & 108.097 .764 & 100,0 & & \\
\hline
\end{tabular}

Las exportaciones de especies de América del Sur se expandieron a una tasa anual del 9,8\% alcanzando hacia el 2011 los US\$309 millones (figura 4). Los principales países exportadores de especias de la región son Brasil y Perú que en conjunto acumulan más del $90 \%$ de las exportaciones de especias de América del Sur. El primero es un fuerte exportador de pimienta, Capsicum sp., clavo y jengibre; mientras que Perú se caracteriza por sus exportaciones de Capsicum sp., jengibre y cúrcuma. Le siguen en orden de importancia Chile y Colombia (tabla 5).

Tabla 5. Exportaciones de especias de América del Sur por país. Valor promedio anual quinquenio 2007-2011 y tasa de crecimiento promedio del decenio 2002-2011 (elaborado en base a datos de United Nations Commodity Trade Statistics Database).

\begin{tabular}{|l|c|r|r|r|}
\multicolumn{1}{|c|}{ Países } & $\begin{array}{c}\text { Promedio 2007-2011 } \\
\text { (US\$) }\end{array}$ & $\begin{array}{c}\text { Procentaje } \\
(\%)\end{array}$ & $\begin{array}{c}\text { Acumulado } \\
(\%)\end{array}$ & $\begin{array}{c}\text { Tasa crecimiento anual } \\
\text { (2002-2011) }\end{array}$ \\
\hline Brasil & 165.594 .678 & 52,6 & 52,6 & 7,8 \\
\hline Perú & 117.318 .300 & 37,9 & 90,5 & 19,8 \\
\hline Chile & 13.455 .084 & 4,4 & 94,9 & $-7,6$ \\
\hline Colombia & 6.554 .061 & 2,1 & 97,0 & 7,7 \\
\hline Ecuador & 4.982 .810 & 1,6 & 98,6 & 15,6 \\
\hline Argentina & 2.116 .741 & 0,7 & 99,3 & $\mathrm{~s} / \mathrm{d}$ \\
\hline Resto & 2.125 .154 & 0,7 & 100,0 & 9,8 \\
\hline América del Sur & 309.146 .826 & 100,0 & & \\
\hline
\end{tabular}


Perú y Argentina, son los países que han expandido a mayor ritmo durante el último decenio sus exportaciones de especias, como indican sus tasas anuales acumulativas del 19,8\% y 15,6\% respectivamente. Llama la atención lo ocurrido por el tercer exportador regional, Chile que es el único país en la región que expone una tasa de crecimiento negativa del $-7,6 \%$.

América del Sur presenta un saldo comercial positivo, casi el $60 \%$ de lo importado (TCA: 11,5\%) corresponde a Brasil, Argentina y Venezuela y las exportaciones, con una TCA de casi el 10\%. Brasil, con pimienta, Capsicum sp., clavo y jengibre y Perú con, Capsicum sp., jengibre y cúrcuma concentran más del $90 \%$ de las exportaciones de especias de América del Sur

\section{CONCLUSIONES}

- Las importaciones mundiales de especias en términos de valor se han mantenido en expansión entre 1992 y el 2011 a similares ritmos de crecimiento como los ocurridos durante las décadas del setenta y ochenta.

- El incremento en casi un $80 \%$ en términos de valor en el último quinquenio analizado de las importaciones mundiales de especias, se debe fundamentalmente al aumento del precio de los commodities agrícolas en general.

- Los principales países importadores se corresponden con aquellas economías que poseen fuertes industrias alimenticias de gran desarrollo o actúan como reexportadotes o centros comerciales destacados de determinadas regiones.

- Tanto las importaciones como las exportaciones de especias en términos de valor, detentan un alto nivel de concentración en unos pocos países. Como importadores sobresalen Estados Unidos, Alemania y Japón; y como exportadores India, China y Vietnam.

- Casi la mitad del intercambio mundial de especias en términos de valor está representado por la pimienta, los productos derivados del género Capsicum sp. y el jengibre.

- Sudamérica, participa de las mismas tendencias observadas a escala mundial, mostrando como región un saldo comercial superavitario en el intercambio de especias.

- Brasil y Perú son los más importantes generadores del saldo comercial positivo de la región, dado que realizan el $90 \%$ de las exportaciones sudamericanas de especias.

- Los restantes países muestran saldos comerciales deficitarios en el intercambio de especias.

- Casi el 60\% de las importaciones de la región lo detentan Brasil, Argentina y Venezuela.

- Perú y Argentina muestran los mayores ritmos de crecimiento de las exportaciones de estos productos durante el último decenio.

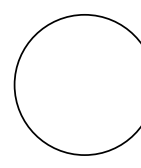

Aghdaie, S.F.A., M. Seidi y A. Riasi. 2012. Identifying the barriers to iran's saffron export by using porter's diamond model. Intl. J. Market. Stud. 4(5), 129-138.

Arizio, O. y Curioni A. 2003. Estudios agroalimentarios. Componente A: Fortalezas y debilidades del sector agroalimentario. Documento 5: Productos

\section{REFERENCIAS BIBLIOGRÁFICAS}

aromáticos y medicinales. Instituto Interamericano de Cooperación Agrícola (IICA), CEPAL y Ministerio de Economía de la República Argentina. Estudio 1.EG.33.7. Buenos Aires.

American Spice Trade Association (ASTA). 2011. Guidance from the American Spice Trade Associa- 
tion. En: www. astaspices.gov; consulta: julio de 2013.

CBI Market Survey. 2010. The spices and herbs market in the EU. En: http://www.cbi.eu/disclaimer; consulta: diciembre de 2012.

Centro de Comercio Internacional. 1982. Especias: Estudio del mercado mundial. Agencia Canadiense de Desarrollo Internacional (CIDA), Ottawa.

Clasificación Uniforme para el Comercio Internacional. 2008. Revisión 4. Departamento de Asuntos Económicos y Sociales, Oficina de Estadística, Naciones Unidas, New York, NY.

Ghorbani, M. 2008. The efficiency of saffron's marketing channel in Iran. World Appl. Sci. J. 4(4), 523-527.

Husain, F. 1996. Tendencias del comercio mundial de especias. Forum de Comercio Internacional 6. Bruselas.

Husain, F. 1992. Tendencias en el mercado mundial de las especias. Forum de Comercio Internacional 2. Bruselas.
International Organization of Spice Trade Associations. 2013. General guidelines for good agricultural practices on spices \& culinary herbs. En IOSTA, http:// www.esa-spices.org/index-esa.html/publicationsesa UNCTAD/GATT; consulta: julio de 2013.

Parthasarathy, V.A., M. Anandaraj, V. Srinivasan, R. Dinesh y K. Nirmal Babu. 2011. Vision 2030. Indian Institute of Spices Research, Kerala, India.

Sahu, P.K. y P. Mishra. 2013. Modelling and forecasting production behaviour and import- export of total spices in two most populous countries of the world. J. Agric. Res. 51(1), 81-97.

Shinoj, P. y V.C. Mathur. 2006. Analysis of demand for major spices in India. Agricultural Econ. Res. Rev. $19,367-376$

Yimer, M. 2010. Market profile spices: Ethiopía. En UNCTAD ITC; http://www.intracen.org / uploadedFiles/intracenorg/Content/Exporters/ Sectoral Information/AgriculturalProducts/Spices /Market\%20Profile \%20on\%20Spices-\%20 Ethiopia.pdf; consulta: julio de 2012 . 